\title{
Developing Environmental Thinking in Manufacturing Companies
}

\author{
Ana Maria Munoz-Marin and Astrid Heidemann Lassen \\ Aalborg University, Center for Industrial Production, Fibigerstræde 16 \\ 9220 Aalborg, Denmark \\ ahl@production.aau.dk
}

\begin{abstract}
This paper presents the development of a process for manufacturing companies to facilitate environmental thinking for the integration of environmental concerns into their business operations. The process takes its point of departure in Corporate Social Responsibility while maintaining focus on obtaining direct benefits for the business. By understanding the end-uses' perception, drivers, limitations and wants in regards to green products, as well as a general understanding of environmental impacts of the product, companies can detect environmental improvement options that are feasible to achieve and which consumers are interested in buying, therefore obtaining results that are good for the business and good for the environment.
\end{abstract}

Keywords: Corporate Social Responsibility, Design for Sustainability, UserDriven strategies, Environmental thinking, Life cycle thinking.

\section{$1 \quad$ Introduction}

The interest in social and environmental responsibility has been increasing at a high rate in both academia and in practice. Companies are gradually being encouraged to consider the ecological and social consequences of their business activities: Governments are creating stronger regulations but also educating consumers as part of the European 2020 strategy for smart, sustainable and inclusive growth (Europe 2020). As a consequence, social and environmental responsibility is moving from being order qualifying to being an order winning variable amongst consumers.

The EU Commission has defined Corporate Social Responsibility (CSR) as; "a concept whereby companies integrate social and environmental concerns in their business operations and in their interaction with their stakeholders on a voluntary basis. Being socially responsible means not only fulfilling legal expectations, but also going beyond compliance" (Commission of the european communities, 2006).

Different reasons lead companies to consider implementing CSR into their activities including ethical, legal, economic and competitive aspects. Such aspects are believed to include benefits such as e.g. 1) giving more options to the customers, 2) being prepared for stronger environmental regulations (legislative and disclosure requirements); 3) positioning the company as market leaders and innovators; 4) being competitive; and 5) developing brand differentiation. 
Research shows that "corporate reputation" is one of the most cited drivers, which includes the perception that consumers have on the company's products and services and the company itself. In the same way, the most common barriers to CSR have been identified as "cost/benefit ratio" and "risk" (Laudal, 2011). Companies and research alike seem to concentrate on the benefits and difficulties of adopting CSR and the importance of communicating and demonstrating their position and business actions towards social and environmental issues: considering internal actions towards the costumers.

In product design is well known the importance of considering the users as the main source of information, not surprisingly, innovation management literature also mention it as a considerable advantage (Chesbrough, 2003). This could also be used towards the integration of environmental issues into the business operation. Involving the users directly into the environmental thinking process will allow understanding the end-users' needs and wishes, which combined with the company strategies, processes and capabilities, will minimize the identified barriers on implementing CSR; resources can be used more effectively and the uncertainty risk can be reduced because the information comes directly from the potential costumers.

However, this inside-out approach leads to a gap in the understanding of CSR as a responsible action that can also bring tangible and intangible benefits to the business if its inputs come from the users unmet needs and desires. The research study reported in this paper targets this gap directly by answering the research question:

RQ1: How could a process for manufacturing companies be developed to facilitate environmental thinking by understanding the end users' perceptions, drivers and limitations, wants and preferences on green products?

This research allows for the development of a general understanding of the company environmental impacts during the product life cycle, involving employees and endusers to find possible solutions. Hereby, the company can detect environmental improvements options that are feasible to achieve and which consumers are interested in buying at the same time, and thereby be able to invest resources more effectively in CSR and work in-depth on the choices which prove valuable.

\section{Methods}

As outlined above, this research builds on the assumption that the premise of obtaining direct benefits for the business while "doing good" is the involvement of the users in the process. In order to research the correctness of such assumptions, the outlined research question is addressed through the following methodological approach.

\subsection{Data Selection}

In order to address the above stated lacks in knowledge, the research addressed in this article takes its point of departure in the research project InnoDoors. The InnoDoors project has the purpose of developing a systematic approach to engaging in userdriven innovation. Amongst others, one of the initiatives in InnoDoors is the aspect of CSR and environmental thinking based on user-integration. The InnoDoors project 
was initiated with the focus on the Danish supply chain surrounding the design, production, sales and implementation of inner doors. InnoDoors has a unique possibility to work with CSR activities and user-integration.

The selected data for the present paper is based on a work package with the purpose of developing a green product-line of doors. This is divided in two different stages: User activities and Internal activities in order to identify the interplay between inside-out and outside-in planned CSR activities.

\subsection{Data Collection}

The data collection was conducted over a period of 1 year, from the summer of 2010 to the summer of 2011, and included a number of different approaches and types of interaction. The different processs of data collection were chosen based on their ability to take the specificities of the industry into consideration, to capture different needs and competences of the users, and to develop the joint comprehension of the new approach to CSR and environmental thinking. In Table 1 is an overview of data collected.

Table 1. Sources of evidence

Sources of evidence

\begin{tabular}{|c|c|}
\hline Interviews & $\begin{array}{l}\text { Individual interviews with selected informants, } \\
\text { experts on each topic. Informants represented } \\
\text { product management, technology management, } \\
\text { environmental specialist, production technical area, } \\
\text { quality management and logistics ( } 8 \text { interviews with } \\
\text { experts and } 6 \text { users) }\end{array}$ \\
\hline Participant observatic & $\begin{array}{l}\text { Two "workshops" were executed for the User, } \\
\text { Internal and Networking activities. Participants } \\
\text { covered users, network partners and internal actors. }\end{array}$ \\
\hline Questionnaires & $\begin{array}{l}\text { One Physical ( } 20 \text { respondents) and one Web-based } \\
\text { questionnaire (with } 116 \text { respondents) on user } \\
\text { perceptions of green products }\end{array}$ \\
\hline
\end{tabular}

Each interaction was documented on video, photos and/or recorder. Conversations were recorded and subsequently discussed with the interviewees, before synthesizing into the frame of case scenarios. Furthermore, the interviews were conducted following the same protocol in order to ensure the reliability of the results as well as reflect the validity of the differences emerging (Yin, 1994). Relevant documentation was additionally provided by the respondents both prior to and after the interviews. This included; strategic documentation, product development roadmaps, customer segmentations and funding proposals. This data has been used to cross reference findings from the interviews and to provide added historical background. The longitudinal approach allowed for a gradual development of the understanding of the industry specificities as well the needs for CSR. 


\subsection{Data Analysis}

The data has been analyzed both in collaborative environments at workshops with project partners and more theoretically. Analytic induction was the main method in the workshops. These results were jointly discussed in order to create a joint understanding. The web based survey was analyzed based on descriptive statistics, as this provided the most meaningful presentation of the results.

\section{$3 \quad$ Analysis and Discussion}

Reduction of energy consumption along with reduction in other emissions (like $\mathrm{CO} 2$ or NOx gasses) (Mortensen, 2011) is a central aspects of the CSR activities in focus in this article. In the context of the construction industry Pohlmann (2002) finds that the Use stage is the most significant for energy consumption. This further underlines the importance of understanding the Use stage and how to impact users.

Approaching CSR from the environmental perspective it emphasizes the relevance of designing and manufacturing products taking into consideration their environmental impacts. Hence the Design for Sustainability (D4S) was considered. The D4S consists of three parts, the first explains the importance of design for sustainability and product innovation; the second presents how to do it in practice; and the third presents reference information like case studies and creativity techniques. Design for sustainability, as its name implies, attempts to go beyond of making "green" products to include the social and economic aspects embraced by the sustainable approach (Crul \& Diehl, 2011). Using the D4S approach facilitates an environmental awareness of the selected product impacts during its life cycle and integrates the users into the innovation process to gain knowledge about their wishes and demands, giving the option to think in possible solutions for environmental impacts that at the same time fulfil the user wants.

In order to develop this environmental thinking and integrate it into the business operation, the data obtained from the workshops, questionnaires and interview were analyzed comparing the actual results with customer perception theory on environmentally friendly products and similar research findings on the field as well as the manufacturing company's strategies in order to obtain coherent results that were aligned with their plans in order to combine efforts and investment in the same direction.

Below, the data is analyzed following the initial conceptual argument; User driven innovation should be conducted in parallel to internal development activities in order to develop environmental CSR initiatives which create an actual impact in the market. We first report the findings of the user analysis conducted, next we report the internal development activities conducted, and thirdly we argue how such activities jointly amount into an agenda for relevant environmental CSR activities.

\subsection{User Analysis}

The web-based surveys show that the most important reason when buying environmentally friendly non-food products is "To save money during its use". It was further found that men are more sensitive to the savings during the purchase, while women tend to think more in the saving during use. The second highest prioritized reason was "Contributing to the environment". 


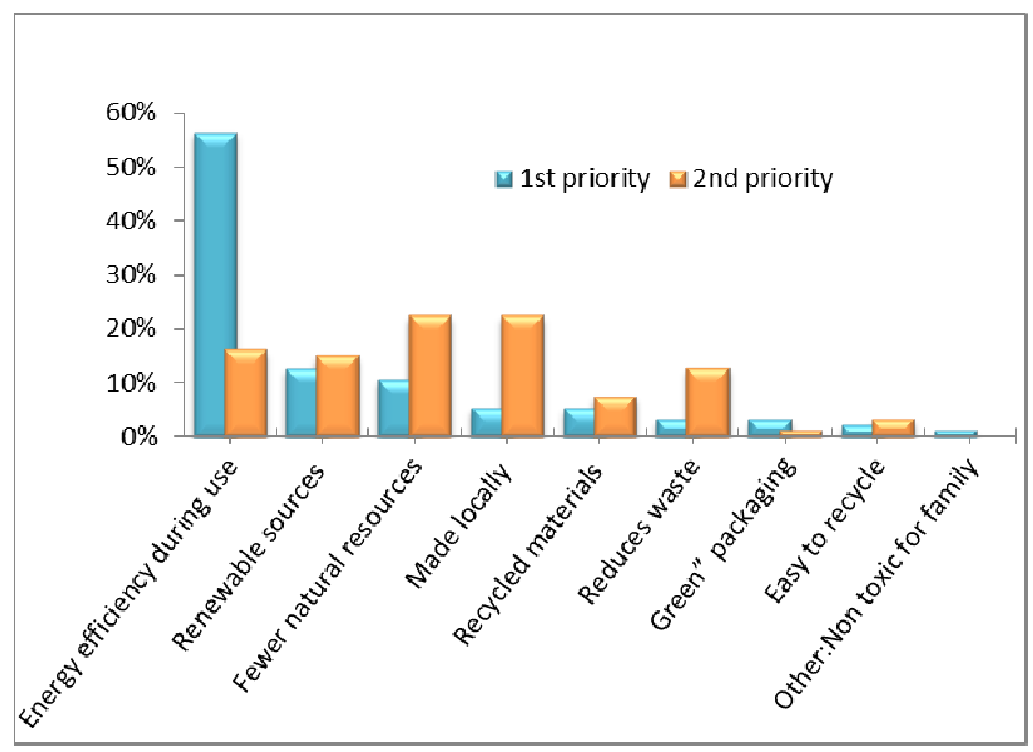

Fig. 1. Most important characteristics for green doors (1st and 2nd)

Price must be a careful decision according to the target group and should not interfere with the green door purchasing, offering variety in green alternatives, providing clear information about the product environmental performance and the product benefits, and last but not least: ensuring reliability. From the survey results there were identified "energy efficiency during use" as the characteristic with higher priority that consumers would like to find in a green door.

This result confirmed the findings from previous research by Muñoz (2010) on this topic where users prioritized: "The door increases energy efficiency" and "the process uses fewer natural resources". This is a positive finding taking into consideration the efforts governments have made on this matter to reduce, or cut, $\mathrm{CO} 2$ emissions and fuel consumption and the tendency of consumers to show a clear preference for the characteristics from the Use stage in the Product life Cycle.

Without a doubt, energy efficiency is a characteristic which is very significant for electronic devises or products that have high consumption of energy during its use. For exterior doors this characteristic can be reflected, for instance, in insulation capabilities. However, when the product in consideration is an interior door, the reduction in energy consumption, although possible, is not significant; therefore other characteristics of the life cycle should be taken into consideration.

The second concept selected as first priority was "The process uses renewable sources (controlled forest, wind energy)". In the case of controlled forest, the case company has already started with the FSC certification, and can continue emphasizing different programs that support it, such as planting new trees or considering the option of including 
"clean energy" into its process. These options have relation with the second priority selected by end-users: "uses fewer natural resources" and "The door is made locally" which is an alternative for reducing $\mathrm{CO} 2$ emissions during transportation.

Limitations are another way to identify what consumers value when buying green products, by analyzing why they do not. The term intention-behavior gap (Sustainability in action sports, 2011) is when consumers have an intention to purchase but find barriers (personal or external) to do it. For the general respondents, the five most important limits are:

Higher price,

Limited product range,

Lack of information about the product environmental characteristics,

Lack of information about the product benefits,

I don't trust that the products are really environmentally-friendly.

A very important result was found when the information was analyzed for the group that corresponds to the case company end-users target group (women between 31-50); although the five limitations are the same as the general respondents, the concept "limited product range" is considered less important than the other four, giving more importance to the concepts associated with lack of reliability: "I don't trust that the products are really environmentally friendly" and lack of information on product benefits and environmental characteristics. The case company, as a company that wants to be recognized for reliability should ensure that, especially its target group trusts the greenness of its doors by offering real environmentally friendly products.

\section{Limitations to buy more green products}

Higher price

11 No availability

1 Limited product range

a I don't trust that the products are really environmentally-friendly

a Lack of information about product's benefits

Lack of information about the product environmental characteristics 20 -

a Lack of interest on environmentally -friendly products

Other: Not time for researching when buying

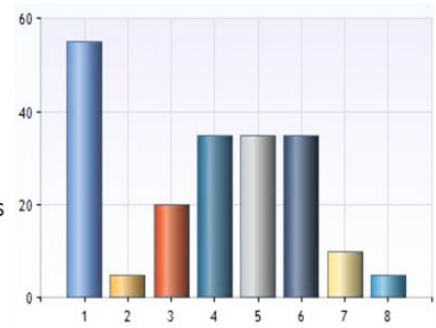

Fig. 2. Limitations to buy more green products. General respondents and the case company end-users actual target groups. 
In total the user analysis of drivers and limitations provides us with the results outline in table 2 . These results will be applied when evaluating the internal development efforts.

Table 2. Drivers and limitations to buy green products

\begin{tabular}{|c|c|c|c|}
\hline \multirow{10}{*}{$\underset{\substack{\vdots \\
\vdots \\
\vdots \\
\vdots}}{1}$} & \multicolumn{3}{|c|}{ Reasons to buy green products } \\
\hline & \multirow{3}{*}{$\begin{array}{l}\text { Environmental } \\
\text { characteristics }\end{array}$} & \multirow{2}{*}{$\begin{array}{l}\text { Save money } \\
\text { during its use }\end{array}$} & $\begin{array}{l}\text { Men are more sensitive to the } \\
\text { savings during purchasing }\end{array}$ \\
\hline & & & $\begin{array}{l}\text { Women tend to think more in the } \\
\text { saving during use }\end{array}$ \\
\hline & & \multicolumn{2}{|c|}{ Contribute to the environment } \\
\hline & \multicolumn{3}{|c|}{ Limitations to buy green products } \\
\hline & \multirow{5}{*}{$\begin{array}{l}\text { Limitations to } \\
\text { buy } \\
\text { green } \\
\text { products }\end{array}$} & \multicolumn{2}{|l|}{ 1.Higher price, } \\
\hline & & \multicolumn{2}{|c|}{ 2.Limited product range, } \\
\hline & & \multicolumn{2}{|c|}{$\begin{array}{l}\text { 3. Lack of information about the product environmental } \\
\text { performance, }\end{array}$} \\
\hline & & \multicolumn{2}{|c|}{ 4. Lack of information about the product benefits, } \\
\hline & & \multicolumn{2}{|c|}{$\begin{array}{l}\text { 5. I don't trust that the products are really } \\
\text { environmentally-friendly (Number } 2 \text { for actual the case } \\
\text { company target costumers - women between } 31-50 \text { years } \\
\text { old) }\end{array}$} \\
\hline
\end{tabular}

\subsection{Internal Development Activities}

The next part of the data analysis focuses on the internal development activities conducted in relation to environmental CSR activities in the case company.

Using different creativity processs during the workshop, the participants from the case company identified their Product environmental impacts during each of the product's life cycle stages: Material (Raw material and Component material), Inhouse manufacture, Distribution, Retail, Use and Disposal. After discussion in the internal team, supported by the environmental specialist, each environmental impact detected was addressed to its root causes: Material use, Energy use, Solid waste or Other emissions. This information was analysed using a qualitative method called Impact Matrix. (Crul \& Diehl, 2011) which relates the environmental impacts in each stage of the product life cycle stages (what are the most relevant impacts and where are generated); and their Root cause (collecting them in main problems). See table 3 
Table 3. Root causes

\begin{tabular}{|c|c|c|c|c|c|c|c|}
\hline \multicolumn{8}{|c|}{ The door environmental impacts related with root causes } \\
\hline & Raw material & $\begin{array}{l}\text { Component } \\
\text { material }\end{array}$ & $\begin{array}{l}\text { In house } \\
\text { manufacture }\end{array}$ & Transportation & Retail & Use & Disposal \\
\hline $\begin{array}{l}\text { Material } \\
\text { Use }\end{array}$ & $\begin{array}{c}\text { Not } \\
\text { controlled } \\
\text { sustainable } \\
\text { wood }\end{array}$ & & $\begin{array}{l}\text { Formaldehyde } \\
\text {, Glue, water- } \\
\text { based paint, } \\
\text { lacquering, }\end{array}$ & $\begin{array}{c}\text { Plastic, } \\
\text { packaging, } \\
\text { transport } \\
\text { material (pallets) }\end{array}$ & & & $\begin{array}{c}\text { not separate } \\
\text { materials, }\end{array}$ \\
\hline $\begin{array}{l}\text { Energy } \\
\text { Use }\end{array}$ & Saw mill & $\begin{array}{l}\text { Making } \\
\text { MDF }\end{array}$ & Processes & \begin{tabular}{|c} 
Fuel \\
consumption (oil, \\
gas)
\end{tabular} & $\begin{array}{c}\text { Exhibition } \\
\text { (light), make to } \\
\text { stock (heating) }\end{array}$ & & \\
\hline $\begin{array}{l}\text { Solid } \\
\text { waste }\end{array}$ & Saw mill & Packaging & $\begin{array}{c}\text { production set } \\
\text { up (paint, } \\
\text { wood), cuts }\end{array}$ & & Packaging & & $\begin{array}{l}\text { Not } \\
\text { information } \\
\text { to the user }\end{array}$ \\
\hline $\begin{array}{l}\text { Other } \\
\text { emissions }\end{array}$ & & $\begin{array}{c}\mathrm{NH} 3 \\
\text { (ammonia) }\end{array}$ & \begin{tabular}{|c} 
VOC (Volatil \\
Organic \\
compounds)
\end{tabular} & $\mathrm{CO} 2$ & & $\begin{array}{c}\text { VOC (Volatil } \\
\text { Organic } \\
\text { compounds) }\end{array}$ & $\begin{array}{c}\text { NOx gasses, } \\
\mathrm{CO} 2\end{array}$ \\
\hline
\end{tabular}

In order to find ideas to reduce the door environmental impacts detected, there were conducted two different Idea Generation workshops. The first one was performed in the focal company with representatives from Material, Manufacture, Product, Quality, Logistics, and Environmental specialist; and the second one, with one representative from the partners according with their capabilities to influence the product value.

Considering the environmental impacts detected, each participant of the internal team selected individually the areas where they consider the case company should focus its efforts. The three priority areas (that obtained the majority of answers) correspond to:

Material Use

Emissions

Energy consumption.

\subsection{Added Value through Environmental Thinking}

By understanding that "Saving money during use" and "Contributing with the environment" are the end-users' most important characteristics to buy green products, and their specific requirements for green doors are "Energy efficiency during use" and "Use of fewer and renewable Natural resources"; combined with the analysis of the Product life cycle workshop performed during the internal activities which defined "Material use",, "Emissions" and "Energy consumption" as their environmental priorities; and the concepts resulting from the Idea generation workshop; an environmental thinking was developed and expressed in terms of Green Values and Initial concepts.

In addition, using the information collected from the end-users about their limitations for buying green products and the communication of environmental characteristics, it was possible to reflect the environmental thinking in terms of concepts for communication and service. 


\section{Conclusion}

Using the suggested approach to environmental CSR, it was possible to collect and analyse information from the end-users and align this with internal capabilities in order to facilitate an environmental thinking into the manufacturing company that led to the understanding of the "green door" meaning and guided to the identification of green values and initial concepts for products and services in order to integrate the environmental concerns into their business operations according to CSR guidelines.

Given the results of the research, we conclude that the suggested process when applied by manufacturing companies facilitates environmental thinking by understanding the end users' perceptions, drivers and limitations, wants and preferences on green products. As mention before, these Green values and initial concepts were inspired in the results obtained throughout the development of different activities during the carrying out of the designed process by combining the users' wishes and demands with the internal possibilities of reducing environmental impacts. With these results, the manufacturing company has an understanding of what green door means for the interested users and is aware of the relevant information that needs to be consider to develop green products. In this way, this process gives them the possibility to create the green values that are feasible for the company to contribute with their Corporate Social Responsibility and at the same time that are significant for the costumers.

\section{References}

1. Commission of the European Communities (2006), http://eur-lex.europa.eu/ LexUriServ/LexUriServ. do?uri=COM : 2006 :0136:FIN : en : PDF (retrieved July 11, 2011)

2. Laudal, T.: Drivers and barriers of CSR and the size and internationalization of firms. Social Responsibility Journal 7(2), 234-256 (2011)

3. Chesbrough, H.: Open Innovation: The New Imperative for Creating and Profiting from Technology. Harvard Business School Press, Boston (2003)

4. Munoz-Marin, A.: Development of a Green product line in JELD-WEN Europe: Creating foundations for innovation through environmental products. Master Thesis, Aalborg University (2010)

5. Crul, D.M., Diehl, M.J.: D4S- Design for Sustainability, http : / www. d4sde.org (retrieved March 2011)

6. Sustainability in action sports, Obstacles that prohibit green consumer behaviour in the context of eco-friendly sports outerwear, Sustainability in action sports (2011), http: //sustainabilityinactionsports.wordpress.com/2011/02/26/ surveyresults-\% (retrieved March 23, 2011)

7. Yin, R.: Case Study Research. Design and Methods, 2nd edn. Sage, Thousand Oaks (1994)

8. Pohlmann: Energy use across the Lifecycle of a house. cited in Tackle Climate Change: Use wood (2002), http: / /www.wrcla.org/pdf/TackleClimateChange.pdf (retrieved March 23, 2011) 